\title{
Erratum to: Measuring and Managing Operational Risk
}

\section{Paola Leone, Pasqualina Porretta and Mario Vellella}

\section{Erratum to: \\ P. Leone et al. (eds.), Measuring and Managing Operational Risk, Palgrave Macmillan Studies in Banking and Financial Institutions, https://doi.org/10.1007/978-3-319-69410-8}

In the original version of the book, the belated corrections from author in Cover, Frontmatter, Chapters 4 and 5 have been incorporated.

The updated online version of these chapters can be found at https://doi.org/10.1007/978-3-319-69410-8_4

https://doi.org/10.1007/978-3-319-69410-8_5

https://doi.org/10.1007/978-3-319-69410-8

(C) The Author(s) 2018

P. Leone et al. (eds.), Measuring and Managing Operational Risk, 